\title{
Utilisation of Seismic Refraction Method in Producing Shale Topography Map of Sungai Batu Ancient River
}

\author{
Sabrian Tri Anda, ${ }^{1,3}$ Rosli Saad, ${ }^{1 *}$ Mokhtar Saidin, ${ }^{2}$ Fauzi Andika, ${ }^{1,3}$ \\ Sabiu Bala Muhammad ${ }^{1,4}$ and Rais Yusoh ${ }^{1}$ \\ ${ }^{1}$ Geophysics Section, School of Physics, Universiti Sains Malaysia, \\ 11800 USM Pulau Pinang, Malaysia \\ ${ }^{2}$ Centre for Global Archaeological Research, Universiti Sains Malaysia, \\ 11800 USM Pulau Pinang, Malaysia \\ ${ }^{3}$ Department of Engineering Geophysics, Syiah Kuala University, \\ Banda Aceh, Indonesia \\ ${ }^{4}$ Department of Physics, Usmanu Danfodiyo University, Sokoto, \\ PMB 2346, Sokoto, Nigeria \\ *Corresponding author: rosli28260@gmail.com
}

Published online: 25 April 2019

To cite this article: Anda, S. T. et al. (2019). Utilisation of seismic refraction method in producing shale topography map of Sungai Batu ancient river. J. Phys. Sci., 30(1), 169-178, https://doi.org/10.21315/jps2019.30.1.12

To link to this article: https://doi.org/10.21315/jps2019.30.1.12

\begin{abstract}
Geophysical methods have been widely used in archaeological prospecting for decades. This is for the fact that the methods provide a great deal of information for archaeologist to determine buried evidences beneath the surface. Geophysical methods are also cost effective, covering much larger area at relatively lower costs, compared with the conventional archaeological probing techniques. The methods are also non-destructive and non-invasive, keeping archaeological sites entirely undisturbed after survey. Several geophysical methods including resistivity, magnetic, gravity, ground penetrating radar and electro-magnetic are usually implemented to map out the archaeological evidences. It is often believed that the seismic refraction method may not be suitable when looking for anomalies of archaeological remains. However, since the purpose of this study is to delineate the boundary of shale to locate the ancient river, seismic refraction can give the very much desired result. The study was conducted at Sungai Batu, Kedah, Malaysia, which is famously known for its archaeological sites, including an ancient international entrepot. The discovery of jetty remains within the study area is also indicative of the existence of ancient river. The results obtained showed that the shale (suspected riverbed) are characterised with P-wave velocity of $>1822 \mathrm{~m} \mathrm{~s}^{-1}$. The suspected ancient river was determine based on a ravine shape that
\end{abstract}


observed. It is believed that shale which is found at a depths of $>15 \mathrm{~m}$ is categorised as ancient river bed. It is concluded that the ancient river was probably flowing from NorthSouth direction towards East.

Keywords: Sungai Batu, Geophysical methods, seismic refraction, shale boundary, ancient river

\section{INTRODUCTION}

Sungai Batu, Kedah, Malaysia is known for its famous archaeological sites. It is believed that the earliest entrepot and religious places are situated in this location. The discovery of jetty remains, iron smelter and religious monuments which were made from clay brick and dated back to $110 \mathrm{AD}$ has proven that these sites are the oldest man-made construction to be recorded in Southeast Asia, as reported by Saad et al. and Nordiana et. al. ${ }^{1,2}$ The geomorphology of mid-south Kedah has totally changed. It is believed that in the 1st-2nd century, this area was recorded as marine and later became a landed region back in 1400 . The reason for these changes could be due to fluctuation of sea level, which has affected the geomorphology of the area, as indicated by Khoo. ${ }^{3}$ According to geological and historical evidence, the fluctuations were about $2-3 \mathrm{~m}$ or less in 200 years. During the late Holocene until recently, the regression of sea level has effected the geomorphological transformation in the area.

The objective of this study is to produce a shale topography map of ancient river using seismic refraction method. This study was triggered by the discovery of jetty remains at the location. Since the study was to be carried out inside the archaeological sites, a non-destructive method was required. One of the most favourable methods to delineate the subsurface materials without destroying existing archaeological records is the use of geophysical prospecting techniques. The techniques provide archaeologist with alternative to explore large areas within a shortest possible time at minimal cost. The techniques also allow archaeologists to determine locations of their next excavation based on the geophysical result available, which enhances the effectiveness of the excavations as explained by Sala et. al. ${ }^{4}$ Integration of several geophysical methods may also go alongside to reducing the ambiguity in interpreting survey results. ${ }^{5}$ However, as peculiar as any research can be, this study is faced with some challenges; the quest to segregate the layer of shale and alluvium deposits and the experience required to interpret shale material itself, without which actual bore logs are needed to assist the geophysical data interpretation. 


\section{EXPERIMENTAL}

\subsection{Study Area}

The study area is situated inside the archaeological complex of Sungai Batu archaeological sites. The area is flat landed and surrounded by palm oil and rubber trees. Several small rivers and swamps can be found at the eastern part of the area. Geologically, the study area is underlain by Mahang formation which consists of sedimentary and granitic rocks. At the northern part, most of the region is covered by granitic rocks, while the rest of the area is covered by sedimentary rocks. It is believed that the sediment itself originated from Gunung Jerai and is transported by a local river (Sungai Merbok) to deposited in this area. ${ }^{6}$ All the rock types found in this area are categorised as shale, sandstone and siltstone orthoquartzite, while the soil types are clay mixed with fine sand (Figure 1).

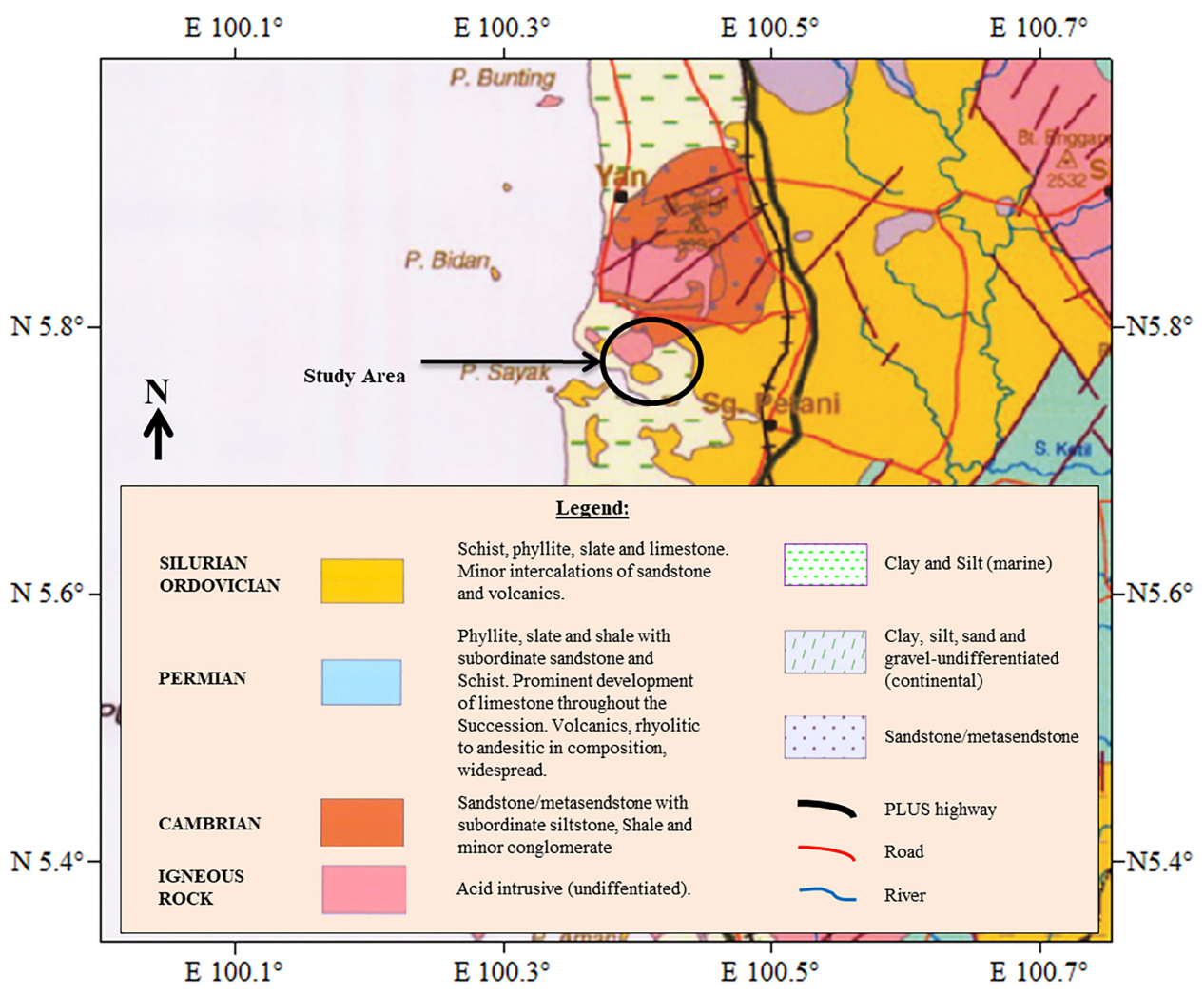

Figure 1: Geological map of Sungai Batu area (Mineral and Geoscience Department Malaysia). ${ }^{7}$ 


\subsection{Methodology}

Despite the fact that seismic refraction method is widely applied to solve a vast number of problems, its application in archaeological prospecting is seldom compared with other geophysical methods such as electrical, ground penetrating radar and magnetic methids. ${ }^{8}$ Since the interest of the study is to determine the potential ancient river by producing shale topography map, seismic refraction method was found suitable to differentiate the boundary between the depositional sediment and shale layer.

Basically, seismic method uses the propagation of elastic wave produced by seismic source to obtain an image of the subsurface. The seismic source can be applied on top of the surface or inside boreholes. ${ }^{9}$ In seismic refraction technique, the method mostly deals with travel time of the refracted waves under critical angle. Two types of body wave are generated for the arrival time measurement: primary wave (P-wave) and shear wave (S-wave). These body waves are distinguished based on the direction of wave propagation relative particle movement. ${ }^{10} \mathrm{P}$-wave has greater velocity than $\mathrm{S}$-wave, hence will arrive first. Illustration of wave propagation and particle movement of body waves are described in Figure 2. In this study, the seismic refraction method only focuses on utilisation of P-wave.
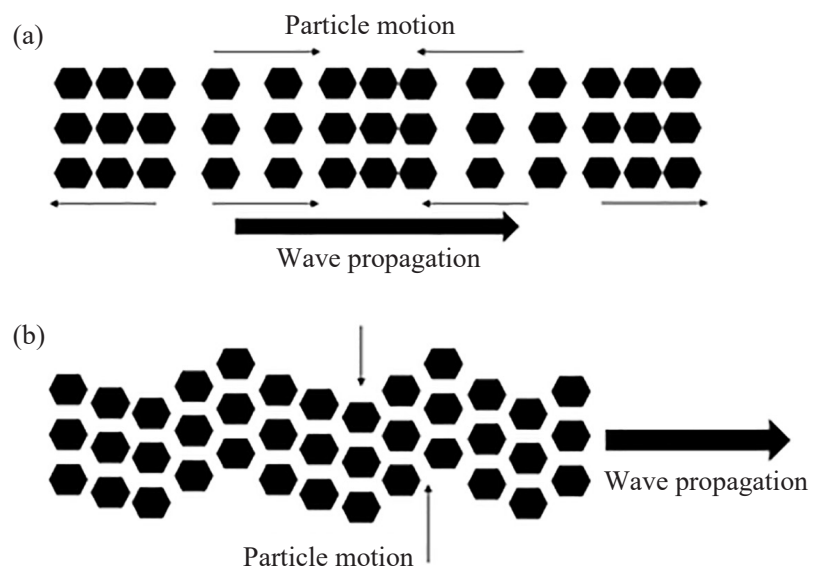

Figure 2: Body waves particles and waves propagation for (a) P-wave, and (b) S-wave.

Figure 3 illustrates the refraction occurring in two different layers of the subsurface. Wave generated from source travels with velocity of $V_{1}$ in first medium and hits the interface between first and second medium. The wave is refracted at critical angle $\theta \mathrm{ic}$ and travels with velocity of $\mathrm{V}_{2}$. This refracted wave is also called a head wave which propagates parallelly through the interface between two different media before refracting back to the ground surface and detected by detectors. 


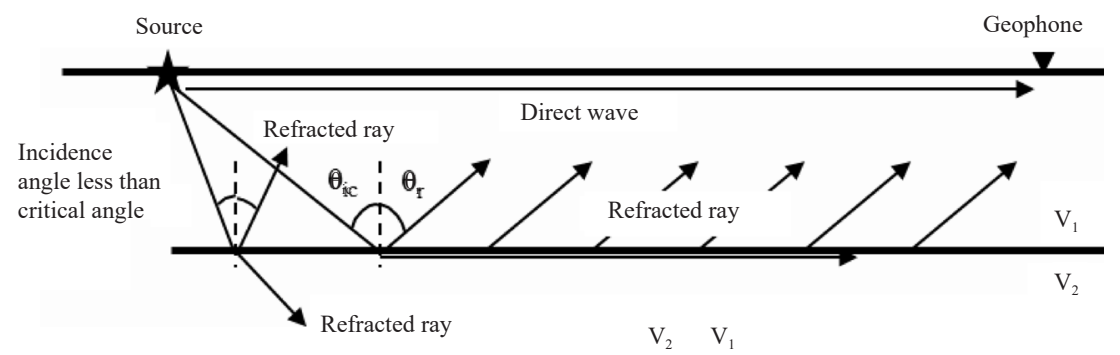

Figure 3: Direct, reflection and refraction waves in seismic study for single subsurface interface, referring to Haeni. ${ }^{11}$

\subsection{Data Acquisition}

The study area consisted of seven seismic refraction lines with varying total lengths. Four seismic lines were conducted inside the archaeological site itself (L1-L4) while the other three lines were conducted at the surrounding area (L5L7), shown in Figure 4. The selected measurement lines were situated to cross the existing river at the eastern part of the archaeological site based on assumption that the existing river is a remain of the suspected ancient river, which is buried by depositional sediment from Gunung Jerai.

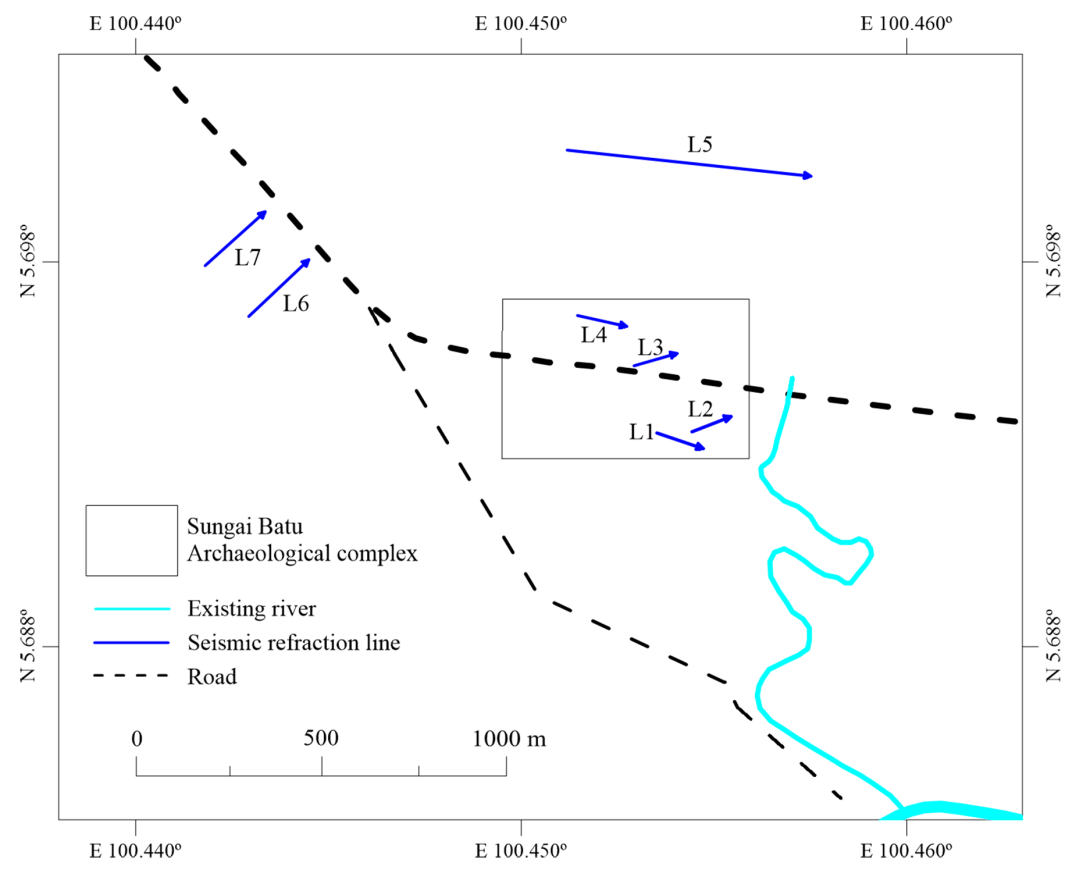

Figure 4: Seismic refraction survey lines at Sungai Batu. 
Lines L1-L4 were designed to have a total length of $115 \mathrm{~m}$ each, while L5 had a total length of $700 \mathrm{~m}$. The rest of lines, L8 and L9 had a total length of $230 \mathrm{~m}$ each. Vertical geophones with natural frequency of $28 \mathrm{~Hz}$ were used as detectors, connected to ABEM MK8 recorder/seismograph using smart cables. Sledgehammer $(5 \mathrm{~kg})$ and weight-drop $(60 \mathrm{~kg})$ were utilised as seismic sources. Illustration of general seismic refraction measurement line with seven shot-points is showed in Figure 5.

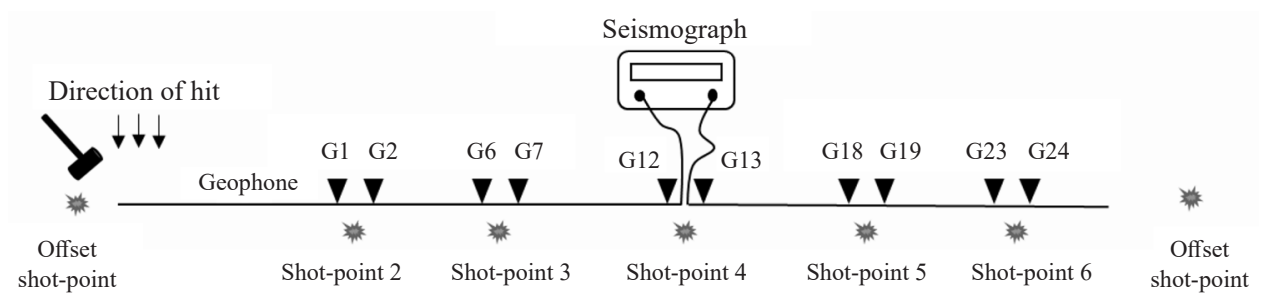

Figure 5: General layout for seismic refraction measurement.

\section{RESULTS AND DISCUSSION}

Seismic refraction tomography results of Lines L1-L7 have identified the P-wave velocity ranging from $250 \mathrm{~m} \mathrm{~s}^{-1}$ to $5000 \mathrm{~m} \mathrm{~s}^{-1}$, with depths varying from $15 \mathrm{~m}$ to $80 \mathrm{~m}$ (Figure 6). To identify the boundary between the depositional sediment and the river bed, all the seismic refraction tomography results obtained were classified into two layers. The first layer is interpreted as moist/saturated alluvium with velocity of $<1822 \mathrm{~m} \mathrm{~s}^{-1}$, while the second layer is interpreted as the river bed, which is made up of shale with velocity of $>1822 \mathrm{~m} \mathrm{~s}^{-1}$. The results of Saad et al. from combination of resistivity and seismic refraction method to identify the Sungai Batu ancient river materials showed that the predicted ancient river bed is made up by shale located at depths ranging from $>10-15 \mathrm{~m} .{ }^{12}$ Comparable results of research conducted by Saad et al. using magnetic method led to a conclusion that the original land of the study area was composed of shale. ${ }^{13}$ Both studies emphasised the importance of identifying shell material as the suspected ancient river bed. 


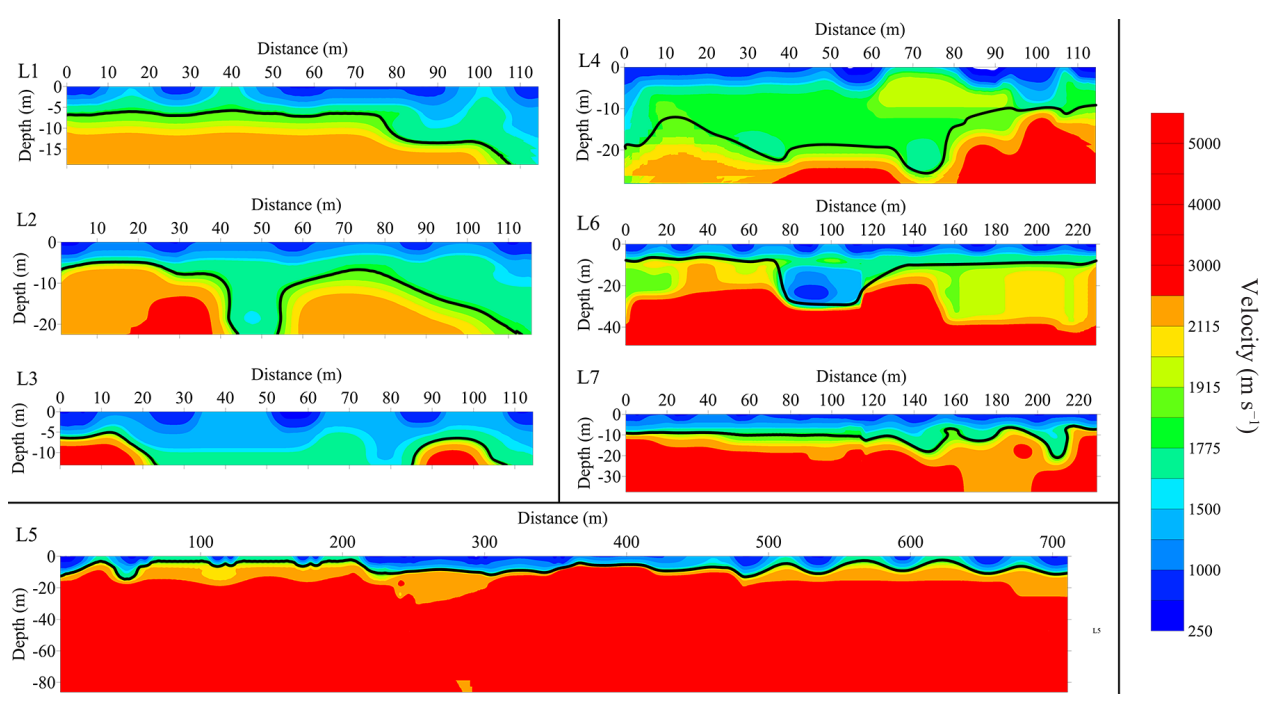

Figure 6: Seismic refraction tomography result for L1-L7 at Sungai Batu.

To predict the direction of the ancient river flow, the depth of shale from the seismic refraction tomography results (Figure 6) were digitised at every $5 \mathrm{~m}$ to generate shale topography contour map of the suspected Sungai Batu ancient river. In most parts, the shale depths are in the range of $2 \mathrm{~m}$ to $30 \mathrm{~m}$. Specific ravine shape patterns were observed, and the shale identified at depths $>15 \mathrm{~m}$ is categorised as the Sungai Batu ancient river bed (Figure 7). The patterns show that the Sungai Batu ancient river was flowing from North-South towards East. The direction of ancient river flow was determine based on the observation of the study area's elevation, since it is believed that the river will flow from a higher altitude to a lower altitude, due to gravity effect (Figure 8). The position of Gunung Jerai itself, which is located at the northern part of study area supports this interpretation. This further indicates that there is a possibility of the ancient river to flow toward the eastern part of study area. 

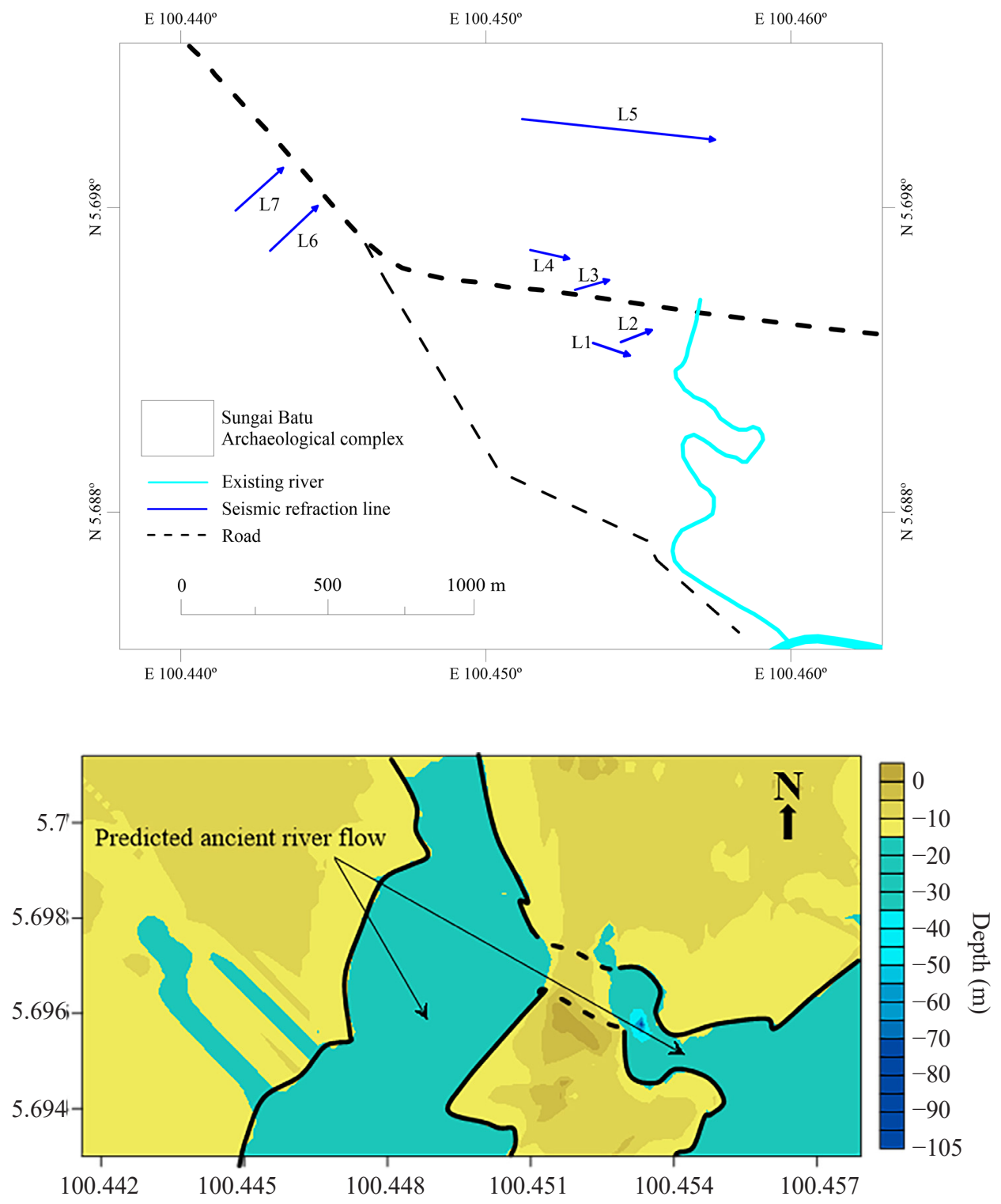

Figure 7: Shale topography contour map digitised from seismic refraction tomography result. 


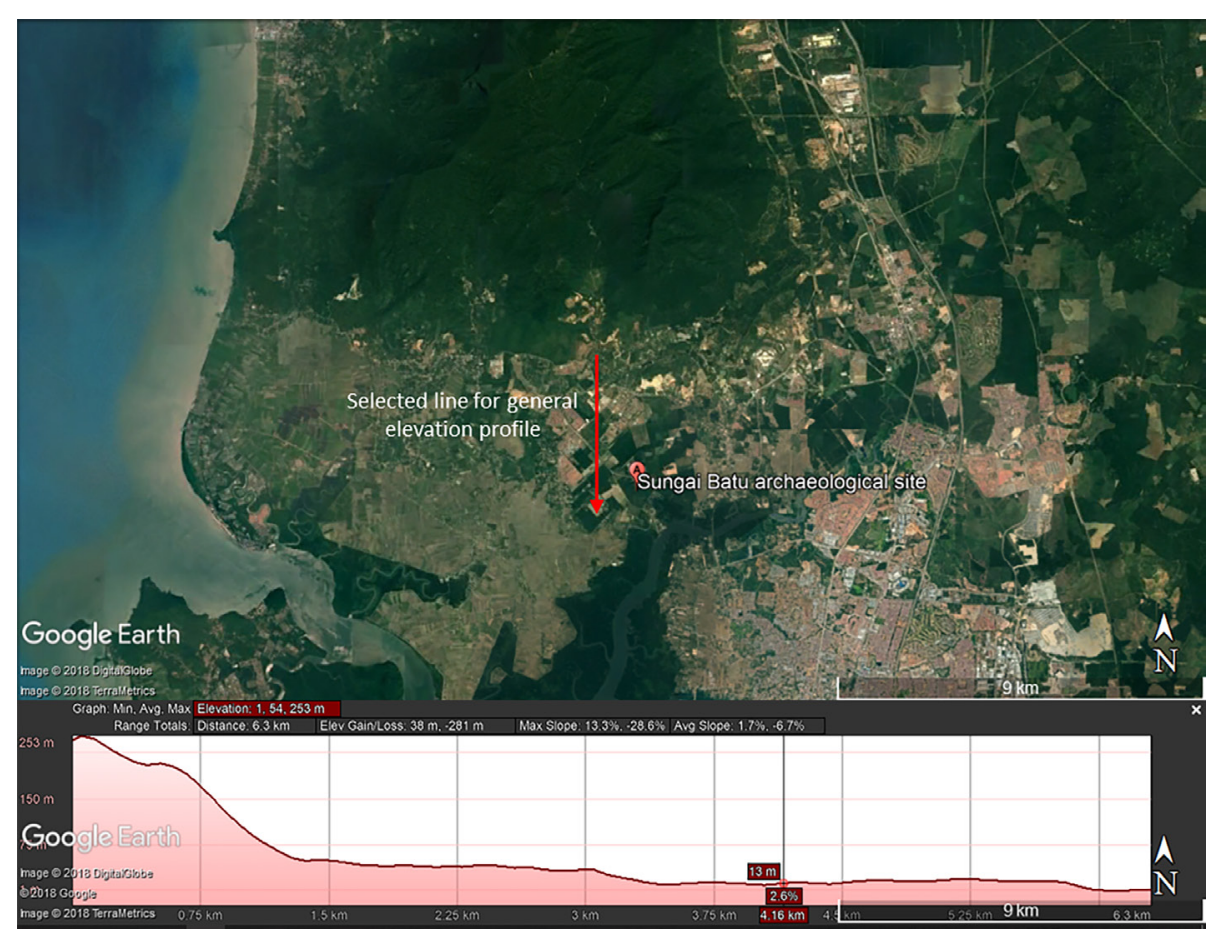

Figure 8: General elevation profile of study area.

\section{CONCLUSION}

The utilisation of geophysical method in archaeological prospecting gives numerous advantages compared to traditional methods. Even though seismic refraction method is rarely applied in archaeological prospecting, the method was found useful in delineating the Sungai Batu ancient river flow. The boundary between alluvial deposit and shale was also identified. The shale layer with velocity of $<1822 \mathrm{~m} \mathrm{~s}^{-1}$ is categorised as river bed. Based on ravine patterns observed, the Sungai Batu ancient river is predicted to flow from North-South towards East direction.

\section{ACKNOWLEDGEMENTS}

The authors would like to thank Universiti Sains Malaysia (USM) Geophysics personnel and postgraduate students for their efforts during the data acquisition and Centre for Global Archaeological Research (CGAR), USM for funding this research, with an account of 1002/PARKEO/910328. 


\section{REFERENCES}

1. Saad, R., Nordiana, M. M. \& Saidin, M. (2014). Resistivity studies of archaeological anomaly at Sungai Batu, Lembah Bujang, Kedah (Malaysia). Electron. J. Geotech. Eng., 19, 2589-2596.

2. Nordiana, M. M. et al. (2014). Archaeological prospection at Lembah Bujang, Kedah (Malaysia) using magnetic and 2-D resistivity method. Electron. J. Geotech. Eng., 19, 4371-4379.

3. Khoo, T. T. (1996). Geomorphological evolution of the Merbok estuary area and its impact on the early state of Kedah, northwest peninsular Malaysia. J. South. Asian Earth, 13(3), 347-371. https://doi.org/10.1016/0743-9547(96)00042-6.

4. Sala, R., Garcia, E. \& Tamba, R. (2012). Archaeological geophysics-from basics to new perspectives. London: InTech.

5. Alashloo, S. M. et al. (2011). Non-invasive geophysical techniques for prospecting the Sungai Batu archaeological site, Kedah, Malaysia. Paper presented at the International Conference on Environmental Engineering and Applications (ICEEA 2011), 10-21 August, Shanghai.

6. Allen, J. (1991). Trade and site distribution in early historic-period Kedah: Geoarchaeological, historic, and locational evidence. Bull. Indo-Pac. Prehist. Assoc., 10, 307-319.

7. Mineral and Geoscience Department Malaysia. (1985). Geological map of Peninsular Malaysia, 8th ed. Kuala Lumpur: Mineral and Geoscience Department Malaysia.

8. Persson, K. (2005). Archaeological prospecting - state of the art. J. Nord Archaeol. Sci., 15, 87-97.

9. Schuck, A. \& Lange, G. (2007). Seismic methods in environmental geology. Berlin: Springer.

10. Doug, C. (2002). Borehole shear-wave surveys for engineering site investigations. California: Geostuff.

11. Haeni, F. P. (1986). Application of seismic-refraction techniques to hydrologic studies. New York: US Geological Survey.

12. Saad, R. et al. (2017). Application of 2D resistivity imaging and seismic refraction tomography to identify Sungai Batu sediment depositional origin. J. Geol. Geophys., 6, 1-5, https://doi.org/10.4172/2381-8719.1000268.

13. Saad, R. et al. (2015). Indentify Sungai Batu ancient river by magnetic method. Electron. J. Geotech. Eng., 20, 11143-11148. 